\title{
A PRODUÇÃO DE PRESENÇA CÊNICA EM DARIO FO: \\ O PENSAMENTO ENCARNADO NA PALAVRA E NA AÇÃO
}

\section{The production of performing presence in Dario Fo: the embodied thought in words and actions}

Sergio Nunes Melo

Universidade Federal de Santa Catarina - UFSC

Resumo: $O$ artigo discute a produção de presença cênica do ator, recentemente falecido, Dario Fo, a partir da fenomenologia da presença cênica de Bert $O$. States. Aborda a interseção entre atuação e dramaturgia como instâncias inseparáveis, relacionadas à própria motivação do ato criador do ator-autor, demonstrando como a trajetória da presença cênica de Fo conseguiu ser uma forma radical de artivismo que habilmente dispensou a doutrinação política.

Palavras-chave: Dario Fo; Presença cênica; Tradição; Artivismo.

Abstract: The article discusses the production of the performing presence of the recently deceased actor Dario Fo drawing upon Bert O. States's phenomenology of the actor's presence. It approaches the interconnectedness of performance and playwriting as inseparable instances related to the very motivation of the creative act of the actor-author, demonstrating that Fo's trajectory of performing presence succeeded in being a radical form of artivism that skillfully dispensed with political indoctrination.

Keywords: Dario Fo; Performing presence; Tradition; Artivism. 
A fenomenologia da presença atorial, de acordo com a visão de Bert O. States, pode ser investigada como um ato discursivo. Ao evocar a expressão "ato discursivo", estabeleço, de saída, um paralelismo entre a vertente fenomenológica empregada neste artigo e um termo teórico seminal bem estabelecido da Linguística e da Filosofia da Linguagem e levado adiante pelo campo de conhecimento das Artes Cênicas. Esse paralelismo visa ressaltar que, assim como 0 ato discursivo, também a presença atorial, como a descreve States, resulta da performance de vários atos, distinguíveis segundo suas intenções. States decupa esse ato em três modos pronominais como estratégias, através das quais 0 ator interage com a plateia. A ênfase colocada em cada um desses modos remete a componentes performativos essenciais do evento espetacular: o primeiro (pronome "eu") é o modo da autoexpressão, em que a destreza psicofísica do ator predomina; o segundo (pronome "tu") é o modo da colaboração, onde a interação direta do ator com os espectadores ganha relevo; e o terceiro é o modo da representação (pronome "ele"), no qual o foco é a veiculação de sentido. Entretanto, States nos adverte de que sua proposta analítica deve ser considerada como uma metodologia de observação, na medida em que:

os modos pronominais [são] pontos de referência ao invés de fases discretas de nossa percepção do ator. Em outras palavras, as tendo separado, provavelmente deveríamos deixar que se reagrupassem numa síntese de percepção, não nos esquecendo de que, mesmo quando uma "suplanta" as outras, elas estão colaborando tanto quanto competindo. A vantagem de pensar no ator nesses termos não é a de aprender algo de novo sobre ele, mas ter uma base melhor para ver como sua atuação desperta nosso interesse não apenas como indivíduos "ocupando uma poltrona no teatro", mas como membros de uma espécie social que "encomenda" ao ator que interprete peças sobre nossas várias questões e nossos vários vícios. ${ }^{1}$ (STATES, 1995, p. 38)

Nesse horizonte, o presente artigo examina a produção de presença cênica em Dario Fo, a partir de suas memórias em entrevistas e declarações, bem como a partir do legado escrito de palestras presenciais dadas por ele pelo mundo afora e transcritas e organizadas por sua esposa, a atriz e dramaturga Franca Rame, com quem, não por acaso, ele compartilhou o Prêmio Nobel de Literatura de 1997, na cerimônia de outorga em Estocolmo, Suécia, num significativo gesto simbólico de reconhecimento de uma parceria de trabalho de seis décadas.

Detentor de um dos prêmios literários mais cobiçados do planeta, ainda que sem ter sido um escritor num sentido mais convencional do termo, Fo entrou para a história mundial do teatro como um homem de múltiplos talentos, pois, além de dramaturgo, foi pintor, desenhista, cenógrafo, figurinista, diretor, compositor e empresário da própria companhia, além de artivista avant la lettre. Não obstante sua versatilidade, foi, por excelência e acima de tudo, um giullare, isto é, um comediante - na falta de uma palavra do vernáculo que traduza com precisão essa figura específica de origem medieval que essencialmente encarna a irreverência. A irreverência é um componente da produção de presença que contempla predominantemente 0 modo pronominal que States denomina como o da representação, pois diz respeito à confrontação de códigos - social, político, cultural, moral etc. Visto que me proponho a salientar o pensamento encarnado de Fo, deixo de lado o substantivo

\footnotetext{
${ }^{1}$ Esta e todas as outras traduções são minhas.
} 
("pensamento") da locução e início a discussão pelos modos que correspondem ao adjetivo ("encamado"), ou seja, os da autoexpressão e da colaboração, que também são constituintes irrenunciáveis do giullare.

Via de regra, Fo tecia seus fios dramatúrgicos no ar rarefeito da improvisação, como nos relata no trecho de uma entrevista ao jornal romano Messaggero, na qual discorre a respeito de um esquete sobre uma situação entre o contador de histórias e uma tigresa:

[A]firmei que representei essa obra durante dois anos consecutivos na base da improvisação, e que só recentemente decidi colocá-la sob a forma escrita. Poucos dias depois, em um outro jornal, saiu uma matéria cujo autor ironizava a minha afirmação, debochava e me tachava de fanfarrão, megalomaníaco e até mesmo de oportunista. (FO, 1998, p. 252)

O que estava em jogo no evento acima relatado diz respeito a uma habilidade atorial específica, pois a improvisação é a arte de se submeter um repertório psicofísico à ação desafiadora de variáveis, tais como tempo, espaço, contexto, estado de espírito, memória, recepção do público, etc. A improvisação como idioma performativo de produção de presença se relaciona tanto ao modo da autoexpressão quanto ao modo da colaboração.

A improvisação é um ato de autoexpressão, na medida em que evidencia que um ator pode fazer o mesmo esquete, o mesmo número, a mesma cena, etc., de modos notadamente diversos. A competência da improvisação corresponde, portanto, ao virtuosismo, ou ao comportamento cênico particularmente extracotidiano, capaz de suscitar o reconhecimento por parte da plateia de que 0 improvisador agrega valor estético ao evento espetacular.

A improvisação é um ato de colaboração porque requer a cumplicidade da plateia no sentido de que uma das convenções adotadas no pacto do evento espetacular seja a da possibilidade do inesperado. A paradoxal expectativa do inesperado envolve não somente a possibilidade da falha (de memória e de ativação de destreza) - o que funciona como fator de risco da cena - como também a de uma invenção espontânea que, exatamente por ser ou parecer única, supostamente ou de fato irrepetível e efêmera, oferece à plateia a oportunidade de gratificação como uma espécie de "bônus" de exclusividade.

Mediante uma análise cuidadosa do método de trabalho de Fo a partir da improvisação, a decisão da Academia Sueca não foi tão inovadora quanto o pensamento crítico, circunstanciado por critérios estabelecidos há apenas alguns séculos, possa nos fazer crer. Haja vista que Homero, que se situa na gênese da literatura ocidental, era 0 autor literário e o executante (ou o performer, se preferirmos uma palavra de origem latina celebrizada no século XX via inglês, ou o aedo, se optarmos por um termo clássico) de sua obra. Assim sendo, a interseção entre 0 ator $e$ o dramaturgo está mesmo mais para a norma do que para a exceção. A propósito dessa cofluência, States sugere que "[u]m modo de se abordar a fenomenologia do ator é considerá-lo como uma espécie de contador de histórias cuja especialidade é que ele é a história que ele está contando" (STATES, 2002, p. 23). 
A abordagem do ator-contador-da-sua-própriahistória, simultaneamente sujeito provedor de conteúdo e objeto observacional do evento teatral, se refere a todos os atores. Mas, podemos dizer que Fo materializou os três modos em plenitude, porque não havia uma divergência entre a razão de ser de seu teatro com propósitos de conscientização sóciopolítica e o resultado estético manifesto na presença cênica. Os modos de autoexpressão e de colaboração estavam, assim, consistentemente subordinados a um compromisso ético: "Se alguém merece o epíteto de comediante no verdadeiro sentido da palavra, é Fo. Com uma combinação de riso e gravidade, ele abre nossos olhos para os abusos e as injustiças da sociedade e também para a perspectiva histórica mais ampla na qual ela pode ser colocada."2 Como não poderia deixar de ser, dado o propósito filantrópico do Prêmio Nobel com benfeitores, principalmente quando suas obras promovem o resgate de dignidade dos oprimidos, o modo da representação (significado) é privilegiado na justificativa da Academia Sueca.

A presença de Fo jorrava de uma fonte ideológica desde sempre. Com seu teatro, além de propor entretenimento de alta qualidade (principalmente através do capricho com o modo da autoexpressão), ele tencionava promover reflexões sobre como devolver ao povo aquilo que tinha sido roubado do povo (significado/ modo da representação), ou seja, um capital cultural popular apropriado pela cultura oficial, elitista, burguesa e culta que, no ato da apropriação, traía os sujeitos de que se apropriava, pervertendo a simplicidade, a sensualidade e a

\footnotetext{
2 The Swedish Academy, Press Release, 09/10/1997,
} 'The Nobel Prize for Literature 1997: Dario Fo. espontaneidade contidas no objeto observacional genuíno.

Provocado por Erminia Artese numa entrevista, quando a professora lhe pergunta se ele tinha encontrado material para suas histórias no repertório de produção culta, Fo respondeu:

O que você entende por produção culta?
A reelaboração que aqueles que cultuam
a tradição popular particularmente dotada
de fantasia fazem das situações que
descobrem naquelas tradições? Se for
isso, saqueei os recolhedoses de todas as
épocas. Por exemplo, fiz um estudo de
todos os tipos de ações cômicas. Eu os
encontrei principalmente nos séculos XV
e XVI. Até mesmo daqueles cujas
matrizes estão em Plauto (para não
recuar muito mais) têm suas origens em
jogos, piadas, situações, difusas entre as
classes incultas. Plauto, que certamente
as conhecia, as recolheu e soube exprimi-
las numa linguagem articulada e compô-
las numa máquina teatral complexa.
Nisso consiste a intervenção do homem
do ofício (não do intelectual como o
concebemos hoje) dos materiais
populares existentes na vida cotidiana, no
modo de divertir-se extemporâneo das
classes assim chamadas "incultas".
(ARTESE, 1977, p. 23)

No que tange à elaboração de um discurso poético cujas falas realmente variavam de acordo com cada apresentação, a presença cênica de Fo contava com um banco de dados vastíssimo, proveniente de uma pesquisa criteriosa. Por um lado, coerente com a formação sistemática que the conferia esses recursos, ainda que autodidata com respeito à articulação verbal, Fo tinha um repertório que cobria, grosso modo, toda a intertextualidade dos temas e autores que lhe interessavam até onde fosse possível alcançar. Não por acaso, vários trabalhos da fase mais madura de Fo foram 
palestras-espetáculos em que ele se colocava diante de um telão, no qual as imagens projetadas the davam as deixas das falas numa espécie de aula magna espetacular com timing perfeito e piadas bem construídas com punch lines garantidos, várias delas tendo como alvos situações político-sociais da Itália de seu tempo, além de outras atemporais. Por outro lado, como ele mesmo declarou várias vezes, era um mentiroso por ofício; por isso, em sua obra presencial, podia haver, em meio ao risco do improviso, umas poucas informações inventadas ou simplesmente equivocadas. Tal falha no modo de representação estava conscientemente prevista: ou não teria sido percebida pela grande maioria, ou teria sido provavelmente perdoada pelos poucos que percebessem diante do extraordinário vigor de seu modo de autoexpressão. Na verdade, qualquer eventual descompromisso com a veracidade de uma fala pode ser visto como uma ação treinada, a de sacrificar o modo de representação no altar do modo de autoexpressão. O depoimento de Fo a respeito de sua infância revela seu reconhecimento da importância capital da mentira como recurso indispensável à produção de presença:

Tudo começa a partir de onde se nasce. Eu nasci num lugarejo do Lago Maggiore, San Giano, perto da fronteira com a Suiça, um lugarejo de contrabandistas e de pescadores ilegais, dois ofícios para os quais não basta ter fígado: é necessário também ter uma grande fantasia. Ora, quem usa a fantasia para transgredir a lei, tem sempre uma parte dessa reservada para divertir os amigos. Naquele ambiente, cada homem é um personagem e, ao mesmo tempo, o autor e o protagonista de uma história que conta. Fiz uma bagagem dessas histórias. Deles aprendi não apenas os conteúdos das histórias, mas também um modo de contá-las. E, acima de tudo, um certo modo de olhar e ler as coisas da realidade, o modo de usar os olhos que tinha aquela gente, classificando todos instantaneamente em personagens ou em coro, em construtores de histórias ou em repetidores (autores e atores), foi a minha arma principal quando cheguei na cidade (para nós "cidade" significa Milão). Dos meus conterrâneos, os que mais me agradavam eram os fabuladores, que passavam pela minha região do Lago Maggiore, contando, nas praças, nas hospedarias, as suas histórias, as quais não tinham lido em nenhum livro. Eram histórias que nasciam da observação da vida cotidiana, cheias de um amargor que se liberava em sátira. Mas, partindo de um caso qualquer, as fábulas deles ganhavam altitude e, com frequência, chegavam aos tons da hipérbole. Contavam sempre em primeira pessoa. Ora tinham posto, por raiva, força demais em lançar o anzol e tinham atingido campanários escondidos no fundo do mar. Ora apostavam corrida mas tinham se esquecido de soltar as amarras e tinham chegado em segundo lugar. Ora tinham bancado os espertos apostando corrida com os caracóis e, quando o caracol, tendo chegado antes, se esborrachava numa pedra, se comoviam e não tinham coragem de comê-lo. (...) Com os fabuladores eu tinha descoberto que existe uma cultura feita daqueles que são sempre definidos como ignorantes, os párias da cultura oficial. Quando mais tarde, fui estudar Arquitetura em Brera (Conservatório de Belas Artes em Milão), me interessando por igrejas românicas, me dei conta de que não eram obras de intelectuais e de artistas classificados como tais, mas de trabalhadores braçais. (ARTESE, 1977, p. 20)

Desde a infância, Fo registrava a canalização da fantasia derivada, por necessidade, da transgressão da ordem, o que não deixa de ser uma enunciação paradoxal do modo de representação (significado) quando o foco está 
sendo posto no modo de autoexpressão (forma). A observação do ator a respeito desses fenômenos sociais é desprovida de um juízo de valor negativo. Pelo contrário, ao afirmar que, para os contrabandistas e pescadores ilegais, era necessário ter mais do que fígado, Fo fez um elogio à astúcia, habilidade essencial a uma arte que tem como cerne, tal qual a própria luta pela sobrevivência, a produção de presença. Em latim, a palavra praesentia, formada pelo prefixo prae (pré, "diante de") e pelo substantivo derivado do particípio presente (tempo que enfatiza a continuidade) do verbo ser/estar, sentia, nos leva a crer que "presença", etimologicamente significa "ato de ser (ou estar) diante de...", ou, melhor dizendo, "ato do sendo (ou estando) diante de...." Presença pode ser lida, então, como ação no tempo (contexto) e no espaço (contexto), a mais precisa definição da arte do teatro a meu ver. Diante da eulogia que Fo faz da astúcia, parece razoável afirmar que a locução adverbial "diante de" implique que a contigência precisa ser integrada com proveito pelo "sendo ou estando", sob pena de sucumbir caso não o faça. Trata-se de uma questão de vida ou morte. Para tal, há que se desenvolver um estado de atenção extraordinário, pois toda presença resulta de uma presença anterior que a prepara e respalda ou a desprepara e dissolve. No caso da presença cênica, além de algum tipo de treinamento, sistemático ou assistemático, quer seja num sistema de ensino-aprendizado, quer seja por autodidatismo, também é fundamental saber roubar, ou seja, eleger predecessores e reconfigurá-los. A esse respeito, fazendo um comentário sobre sua articulação vocal, Fo afirmou que:

[s]omente os pontos essenciais são indicados, o restante é atirado fora com grande velocidade, como se fosse picado no interior de um implacável morder de palavras, sem pausas nem respirações. Há um famoso trecho do Arlecchino que narra um fato que já é do conhecimento de todo o público. Nesse caso, o recontar também é feito a partir da mesma síntese acelerada. Eis aí a razão de minha insistência em dizer o quanto é importante conhecer os temas, as situações, os andamentos de nossa tradição. Por quê? É uma questão de acumular uma bagagem de conhecimentos, a mais rica possível, à qual podemos recorrer sempre que surgir uma dificuldade, permitindo-nos solucionar de modo original uma passagem. Sempre declarei ser um grande ladrão: roubo soluções, achados de quem quer que seja... mas também tenho que alertá-los que, para roubar bem, precisamos estar olhando ao redor o tempo todo. (FO, 1998, p. 245-246)

Olhar ao redor o tempo todo remete novamente a um estado de atenção que requer treinamento prévio. Entretanto, na produção de presença de Fo, a coexistência de preparo e reação ao acaso era uma constante ao invés de ser uma variável. A visão de Fo sobre a Commedia dell'arte, movimento posterior ao aparecimento dos giullari, que ele também saqueou consideravalmente, nos mostra uma perspectiva não usual da produção de presença improvisacional desses atores que é consistente com a visão de States dos modos de autoexpressão e de colaboração.

Os cômicos possuiam uma bagagem incalculável de situações, diálogos, gags, lengalengas, ladainhas, todas arquivadas na memória, as quais utilizam no momento certo, com grande sentido de timing, dando a impressão de estar improvisando a cada instante. Era uma bagagem construída e assimilada com a prática de infinitas réplicas, de diferentes espetáculos, situações acontecidas também no contato direto com o público, mas a grande maioria era, certamente, fruto de exercício e estudo. (FO, 1998, p. 17) 
Diante da aporia da presença improvisada preparada para sê-lo, Fo promovia a exposição do ato de criar, no qual um evento teatral emergia não somente de um alto nível de entretenimento, mas também de um discurso político. Por isso, fez questão de eliminar a quarta parede. Em sua concepção de presença, estava implícita a rejeição a qualquer tipo de estrelismo, bem como a qualquer forma hierárquica de teatro convencional. Seu desempenho atorial, por si só, constituía teatro épico popular, ou seja, sem resvalos na reflexão tediosa nem na doutrinação massante, e sim com ênfase numa crítica marxista das injustiças e das instituições da sociedade. Citando o artista do Renascimento, Rafael Sanzio, na palestraespetáculo Picasso Desnudo, Fo afirmou que "é preciso lutar contra a opressão até se esfolar" (FO, 2012). O animal político de Fo, um homem que respondeu a cerca de duzentos e cinquenta processos judiciais e que teve duas breves passagens pela prisão e a esposa estuprada por um grupo de extrema direita que os considerava um casal de terroristas, Ihe fornecia força motriz suficiente para não desperdiçar energia com tensões musculares desnecessárias ou afetações ou lapsos de memória que chegassem a ser notados pela plateia. Para que esse estado, ou dinâmica, de presença cênica seja mantido, um ator precisa ter o que, em português do Brasil, chamamos de "jogo de cintura", flexibilidade:

[O] que distingue os grandes atores dos medianos é sua souplesse. [...] Eles têm um grande conhecimento de técnica de atuar e estão tão envolvidos no que estão atuando que não precisam fazer alarde... Não mostram que estão se esforçando. Eles nos fazem esquecer que estão atuando. (apud ARTESE, 1977, p. 40-41)
Tendo pertencido a um movimento não organizado denominado de "teatro físico", Fo foi aluno de Jacques Lecoq, o mestre da "mímica de fundo", uma mímica menos rigorosa do ponto de vista de convenções (tais como pontos fixos e perfeccionismo extremado da execução dos movimentos) e mais flexível do que a mímica clássica, uma mímica que põe em jogo a faculdade inesgotável de criar através de uma interação do ser criativo com o mundo enquanto linguagem que se pode compreender e "falar". Boa parte do treinamento com a metodologia lecoquiana consiste em educação do movimento. Não está em jogo, para a abordagem do mestre francês, o virtuosismo do movimento, ao contrário da mímica clássica, mas a conscientização das capacidades do corpo. Lançando um dilema entre "aludir" e "imitar", Fo deixou um relato sobre detalhes técnicos a respeito da síntese da flexibilidade, resultante da preparação no momento de risco do improviso. O relato é sobre o caminhar de uma tigresa:

Há trinta anos, durante a montagem de Ditto nell'occhio (Dedo no olho), ao lado de Lecoq, aprendi a demarché (modo de andar) do felino: agachar-se - como se fosse andar de gatinhas, distender-se, alongar o braço esquerdo dobrando o pulso para dentro, alongar para frente a perna direita, prosseguir então com souplesse (flexibilidade), alternando, durante 0 movimento, a perna esquerda com o braço direito e vice-versa. Parece algo simples, mas na realidade não o é. Mas não é esta a questão. A questão é que, mesmo conhecendo essa caminhada, que é elegante, de efeito e aproxima-se bem da real, eu não a usei durante toda a representação. Por quê? Para evitar ser descritivo, é justamente isso, pois teria banalizado o conto, em vez de reforçá-lo. É 
preciso reunir a coragem e a inteligência de aludir em lugar de realizar a descrição completa. Pôr em foco certos detalhes e deixar escapar outros. Isso determina um estilo e um ritmo mais densos e compactos na narrativa da história. (FO, 1998, 241-242)

Ao relatar a tensão entre o conhecimento de uma coreografia adquirida via treino e a escolha de não utilizar esse conhecimento como uma forma petrificada, ainda que perfeita, Fo revelou algo sobre o seu modo de produção de presença. Ao escolher a alusão em detrimento da descrição, que poderia ter levado o conto à banalização, apesar do capricho formal dos movimentos, Fo parecia sugerir que o engajamento físico, emocional e mental, exigido na arte da presença cênica, está além das "garantias" de conhecimentos acumulados, na medida em que ser ou estar diante do público com uma mensagem definida e um instrumento afinado não exime o ator do desafio de adesão à emergência, da presentificação diante do "perigo" do devir da cena. Esse princípio ordenador, embora diga respeito mais explicitamente ao modo de autoexpressão, também permeia o modo de representação, não somente porque ele tinha o que dizer, o que não é pouco, mas também porque a agudeza do espírito é mais adequada à provocação do discurso político do que a comoção do drama ou a contemplação silente da tragédia.

No que diz respeito a Fo (e provavelmente a todos os atores que deixam marcas históricas), a consistência do modo de representação (significado) foi imprescindível no estabelecimento e na manutenção do pacto entre o ator e a plateia quanto ao valor e à adequação dos temas abordados em prol da comunidade humana. Afinal, é o compartilhamento de conteúdo na composição cênica o que dá sentido a haver um evento tão específico em que há atuantes e recipientes mesmo quando seus limites de interação não sejam nítidos, de modo que o teatro siga sendo um modo extraordinário de conscientização de nossa cultura, de nossas origens, de nosso passado, de nossos obstáculos para o futuro, de nosso presente, de nossa presença.

Recebido em 26/11/2017

Aceito em: 06/02/2018

\section{Referências Bibliográficas}

ARTESE, Erminia. Dario Fo parla di Dario Fo. Cosenza: Lerici, 1977.

FO, Dario; RAME, Franca. Dario Fo and Franca Rame Theatre Workshops at Riverside Studios, London, 28 April, 5, 12, 13 and 19 May, 1983. London: Rednotes, 1983.

FO, Dario; RAME, Franca (Org.). (1987) Manual Mínimo do Ator. Tradução de Lucas Baldovino e Carlos David Szlak. São Paulo: Editora SENAC São Paulo, 1998.

FO, Dario; RAME, Franca. Picasso Desnudo. Palestra-espetáculo, com direção cênica de Dario Fo e direção de video de Ben Fatto, filmado no Teatro dal Verme, Milão, em 19/12/2012. Disponível em: $<$ http://www.rai5.rai.it/articoli/picassodesnudo/29688/default.aspx>. Acesso em 26/09/2017.

SCUDERI, Antonio. Dario Fo and Popular Performance. New York: Legas, 1998.

STATES, B. O. (1995) The Actor's Presence: Three phenomenal modes. In: Acting (Re)Considered: A theoretical and practical guide. ZARRILLI, Phillip B. New York: Routledge, 2002. pp. 23-39.

\section{Nobel Prize for Literature Press}

Release, disponível em: $<\mathrm{http}: / /$ www.nobelprize.org/nobel_prizes/literat ure/laureates/1997/press.html>. Acesso em $17 / 09 / 2017$ 